\title{
Research on Permanent Magnet Synchronous Motor Speed Control System Based on Three-Order Linear Active Disturbance Rejection Controller
}

\author{
Zhipeng Chen, Huazhang Wang*, Wei Zheng \\ College of Electrical \& Information Engineering, Southwest Minzu University, Chengdu 610041, China \\ Email: 18328086772@163.com
}

\begin{abstract}
Linear active disturbance rejection control (three-order LESO+PD control) and fuzzy PID control strategies are used to simulate the same permanent magnet synchronous motor with variable speed (constant load) and variable load (constant speed), by observing and analyzing the oscilloscope waveform data and waveform changes in Matlab/Simulink, we can compare the control performance of the two control algorithms under different conditions. By comparing the waveform changes of the oscilloscope, it is found that LADRC has more advantages in real-time than fuzzy PID, and the fluctuation is smaller after stabilization. However, the linear auto disturbance rejection control algorithm is more likely to cause overshoot, and it is not as easy to master as fuzzy PID in parameter adjustment. The two control algorithms have their own advantages and disadvantages.
\end{abstract}

Keywords: permanent magnet synchronous motor, linear active disturbance rejection control, linear state observer, fuzzy PID control.

\section{$1 \quad$ Introduction}

Permanent magnet synchronous motors (PMSM) are widely used in robots, electric vehicles and machine tools, low-power applications and high-performance drives ${ }^{1}$, and have begun to replace brush motors in various application fields. However, the mathematical model of permanent magnet synchronous motor (PMSM) is nonlinear, multivariable and strong coupling ${ }^{2}$, so it is not easy to achieve accurate control. We would like to draw your attention to the fact that it is not possible to modify a paper in any way, once it has been published. This applies to both the printed book and the online version of the publication.

In order to achieve excellent control of permanent magnet synchronous motor (PMSM), because of its weak adaptability to changeable environment and low control precision, many scholars and engineers are constantly exploring control algorithms with more accurate control accuracy and stronger antidisturbance ability. With the enhancement of the depth and breadth of theoretical analysis, today's PID has become more and more intelligent. At present, the more common intelligent PID control includes fuzzy PID, neural network PID, particle swarm fuzzy PID, etc ${ }^{3,4,5}$. Professor Han Jingqing of the Chinese Academy of Sciences started from the principle of traditional PID in the late 1980s, analyzed its advantages and disadvantages theoretically, combined with modern control theory, combined tracking differentiator (TD), extended state observer (ESO), nonlinear State Error Feedback Control Rate (NLSEF) combines a new type of controller-Active Disturbance Rejection Controller (ADRC) ${ }^{6}$. The algorithm proposed by Professor Han Jingqing attracted a large number of scholars' onlookers and research. Active disturbance rejection control absorbs the essence of classic control theory and combines it with modern control theory. The total disturbance is estimated in real time through ESO and eliminated by NLSEF, thereby enhancing the anti-disturbance ability of the system ${ }^{7}$. However, because ADRC itself needs to adjust many parameters, if some parameters are not adiusted well, the control effect is not as good as traditional PID control, and thus it has not been highly recognized by the engineering community. Based on the theory proposed by Professor Han Jingqing, Dr. Gao zhiqiang transformed nonlinear active disturbance rejection control (ADRC) into linear Active disturbance rejection control (LADRC), thus simplifying the technique of active disturbance rejection control (ADRC). The basic idea is: 1. Linearize ESO to simplify the design of ESO; 2. Linearize NLSEF and use a simple PD combination to replace the previous NLSEF ${ }^{8}$. This makes the design of the control system 
simple and intuitive, the controller parameters are greatly reduced to three, and the anti-disturbance performance is not worse than the performance of the control algorithm proposed by Professor Han Jingqing, which is becoming a hot spot in engineering applications.

In this paper, through analysis and mathematical modeling of permanent magnet synchronous motor, the ideal stator voltage equation of permanent magnet synchronous motor under d-q axis is obtained. According to the characteristics of the motor, the third-order linear active disturbance rejection control algorithm and the fuzzy PID control algorithm are designed respectively, and the algorithm model is built in Matlab/Simulink. By observing and analyzing the oscilloscope waveform data and waveform changes in Matlab/Simulink, the advantages and disadvantages of the control performance of the two control algorithms under different conditions are compared.

\section{$2 \quad$ PMSM Mathematical Model}

Because the permanent magnet synchronous motor system is a complex system, in order to simplify the analysis, in the process of motor simulation, assuming that the PMSM is an ideal type, it is satisfied:

1) Ignore the saturation of the motor core;

2) The eddy current and hysteresis loss in the motor are negligible;

3) The current in the motor is a symmetrical three-phase sine wave current ${ }^{9}$.

In this way, the stator voltage equation of the permanent magnet synchronous motor in the d-q axis coordinate system can be equivalent to the following form:

$$
\left\{\begin{array}{l}
u_{d}=R i_{d}+\frac{d}{d t} \psi_{d}-\omega_{e} \psi_{q} \\
u_{q}=R i_{q}+\frac{d}{d t} \psi_{q}+\omega_{t} \psi_{d}
\end{array}\right.
$$

The stator flux equation is:

$$
\left\{\begin{array}{l}
\varphi_{d}=L_{d} i_{d}+f_{r} \\
\varphi_{q}=L_{q} i_{q}
\end{array}\right.
$$

Substituting equation (2) into equation (1), the stator voltage equation can be obtained as:

$$
\left\{\begin{array}{l}
u_{d}=R i_{d}+L_{d} \frac{d}{d t} i_{d}-\omega_{e} L_{q} i_{q} \\
u_{q}=R i_{q}+L_{q} \frac{d}{d t} i_{q}+\omega_{r}\left(L_{d} i_{d}+\psi_{f}\right)
\end{array}\right.
$$

where $u_{d}$ and $u_{q}$ are the d-q axis components of the stator voltage respectively; $i_{d}$ and $i_{q}$ are the d$\mathrm{q}$ axis components of the stator current respectively; $R$ is the stator resistance; $\varphi_{d}$ and $\varphi_{q}$ are the d-q axis components of the stator flux linkage; $\omega_{e}$ is the electrical angular velocity; $L_{d}$ and $L_{q}$ are the dq inductance components respectively; $\psi_{f}$ represents the permanent magnet flux linkage.

The electromagnetic torque equation at this time can be written as:

$$
T_{e}=\frac{3}{2} p_{n} i_{q}\left[i_{d}\left(L_{d}-L_{q}\right)+\psi_{f}\right]
$$

In addition, in the process of building the motor model, we should pay attention to:

$$
\left\{\begin{array}{l}
\omega_{e}=n_{p} \omega_{m} \\
N_{r}=\frac{30}{\pi} \omega_{m} \\
\theta_{e}=\int \omega_{e} d t
\end{array}\right.
$$

wherein, $\omega_{m}$ is the mechanical angular velocity of the motor, the unit is $\mathrm{rad} / \mathrm{s} ; N_{r}$ is the speed of the motor, and the unit is $r / \mathrm{min}$. 


\section{Controller Design}

\subsection{The Design of Linear Active Disturbance Rejection Controller}

The basic structure of LADRC is shown in Figure 1. LADRC is mainly composed of two parts: Linear State Observer (LESO) and Proportional Derivative (PD) linear combination control law.

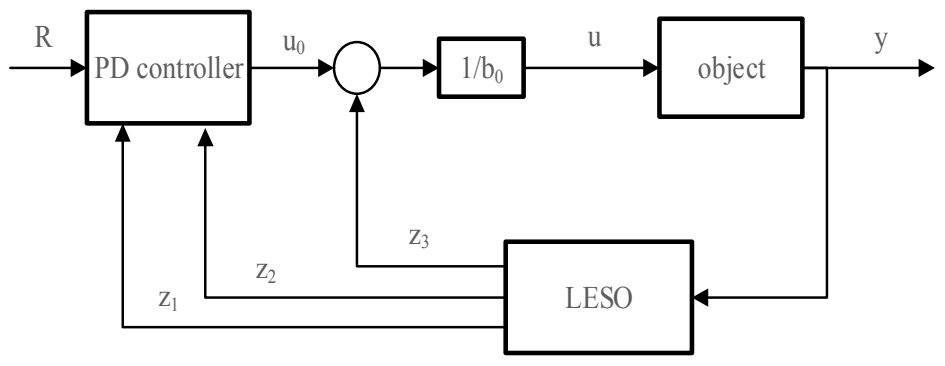

Figure 1. Basic structure of LADRC

Taking the second-order system as an example, the controlled object can be expressed in the following form:

$$
\ddot{y}=f(y, \dot{y}, w, t)+b u=-a_{1} \dot{y}-a_{0} y+w+b u
$$

where $y$ and $u$ are the output and input of the system, and $w$ is the disturbance. $a_{0}, a_{1}, w$ are unknown, part $b$ is known (known part is $b_{0}$ ), then (6) can be written as:

$$
\ddot{y}=f(y, \dot{y}, w, t)+b u=-a_{1} \dot{y}-a_{0} y+w+\left(b-b_{0}\right) u+b_{0} u=f+b_{0} u
$$

where $f=-a_{1} \dot{y}-a_{0} y+w+\left(b-b_{0}\right) u$ is the total disturbance, and the total disturbance includes internal disturbance and external disturbance.

Select state variables:

$$
\left\{\begin{array}{l}
x_{1}=y \\
x_{2}=\dot{x} \\
x_{3}=f
\end{array}\right.
$$

Then the expanded state space of equation (2-2) can be written as:

among them

$$
\left\{\begin{array}{l}
\dot{x}=A x+B u+E \dot{f} \\
y=C x+D u
\end{array}\right.
$$

$$
A=\left[\begin{array}{lll}
0 & 1 & 0 \\
0 & 0 & 1 \\
0 & 0 & 0
\end{array}\right], B=\left[\begin{array}{l}
0 \\
b_{0} \\
0
\end{array}\right], E=\left[\begin{array}{l}
0 \\
0 \\
1
\end{array}\right], D=\left[\begin{array}{l}
0 \\
0 \\
0
\end{array}\right], C=\left[\begin{array}{lll}
1 & 0 & 0
\end{array}\right]
$$

Since $f$ can be estimated according to the correction term, $f_{0}$ can be omitted, and the linear extended state observer obtained according to equation (9) is

$$
\left\{\begin{array}{l}
z=[A-L C] z+[B, L] u_{c} \\
y_{c}=z
\end{array}\right.
$$

where $z$ is the state vector of the observer, and $L$ is the observer error feedback gain matrix, $u_{c}=[u, t]^{T}$ is the combined input. $y_{c}$ is the output, in order to put the poles of the characteristic equation at the same position so that ${ }^{10}$

$$
\lambda(s)=|s I-(A-L C)|=\left(s+\omega_{0}\right)^{3}
$$

select the gain matrix of the observer $L=\left[\begin{array}{lll}3 \omega_{0} & 3 \omega_{0}^{2} & \omega_{0}^{3}\end{array}\right]$. 
Another component of LADRC is the linear error feedback control law (LSEF). Since ESO can estimate and compensate the total disturbance in real time, LESO can be further simplified to the PD combination design, and the integrator in the traditional PID design can be omitted. Therefore, for the second-order system, the form of PD controller used by LDRC is

$$
u_{0}=k_{p}\left(r-z_{1}\right)-k_{d} z_{2}
$$

Among them, $r$ is the reference value (system setting value), $z_{1}$ and $z_{2}$ are the states of the LESO observer, and $k_{p}$ and $k_{d}$ are the proportional and integral amplification factors in the PD controller, respectively. The model designed this time adopts the LESO of the first order. In this way, in order to make the transfer function of a second-order system without zeros and only poles:

$$
s^{2}+k_{d} s+k_{p}=0
$$

So we can choose $k_{p}=w_{c}^{2}, k_{d}=2 w_{c}$, where $w_{c}$ is the controller bandwidth.

According to the mathematical model of LESO and PD controller, the simulation model of LADRC can be built in Matlab/Simulink as shown in Figure 2:

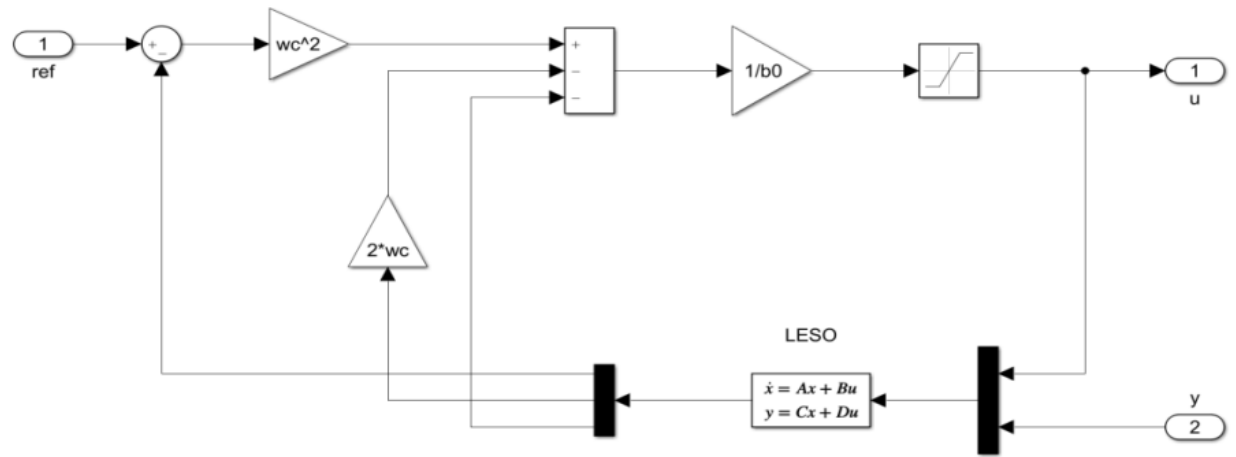

Figure 2. Third-order LADRC Matlab/Simulink simulation model

Fuzzy control

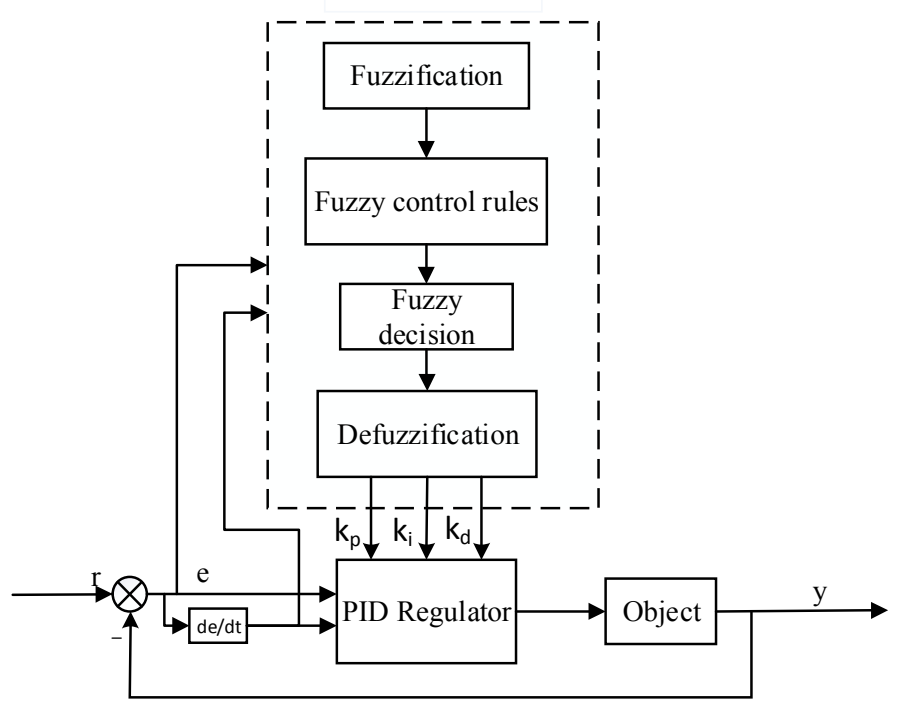

Figure 3. Block diagram of fuzzy PID structure

\subsection{Fuzzy PID Controller Design}

The fuzzy PID controller is a combination of the PID controller and the fuzzy controller. The input of the fuzzy controller is the deviation $e$ and the deviation change rate $e_{c}$. The input is fuzzy, fuzzy 
judgment, and de-fuzzy, and finally $k_{p}, k_{i}, k_{d}$ Output, so as to realize real-time modification of PID parameters. Because the three parameters $\left(k_{p}, k_{i}, k_{d}\right)$ in the fuzzy PID controller change in real time according to the change of the control environment, it can meet the control requirements under different conditions ${ }^{11}$. The block diagram of the fuzzy PID controller is shown in Figure 3, where $e$ is the system deviation, which represents the difference between input $r$ and output $y$, the expressions of $k_{p}, k_{i}$, and $k_{d}$ are as follows:

$$
\left\{\begin{array}{l}
k_{p}=k_{p 0}+\Delta k_{p} \\
k_{i}=k_{i 0}+\Delta k_{i} \\
k_{d}=k_{d 0}+\Delta k_{d}
\end{array}\right.
$$

When designing a fuzzy PID, the first thing to determine is the structure of the fuzzy controller, the fuzzy processing of input and output parameters, where the input is the error $e$ and the error change rate $e_{c}$, and the output is $k_{p}, k_{i}$, and $k_{d}$.

The language value of input and output and the choice of membership function are shown in Figure 4 and Figure 5 below:

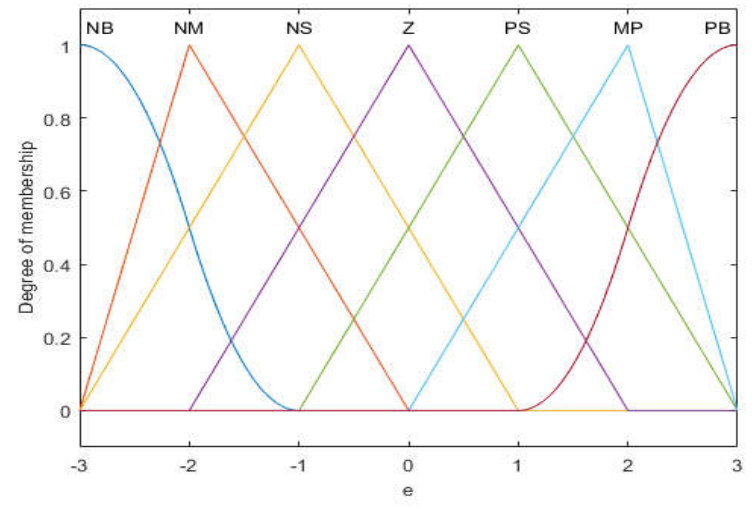

Figure 4. Linguistic value and membership degree of $e$ and $e_{c}$

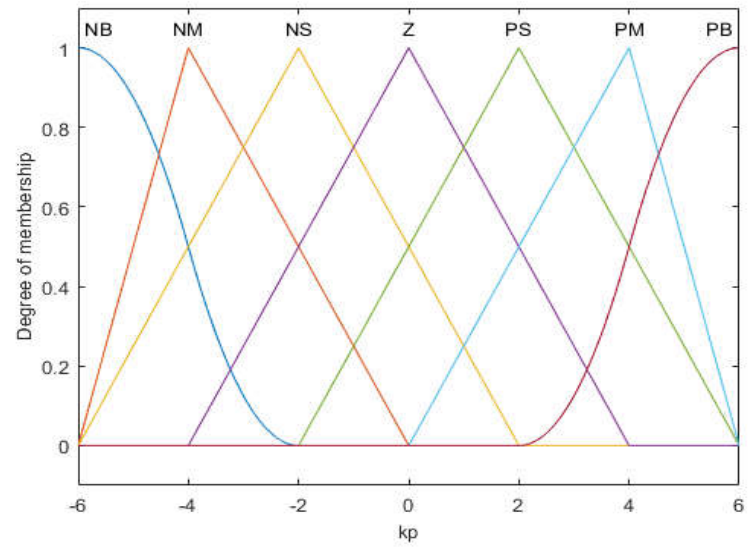

Figure 5. Linguistic value and membership degree of PID parameters

Fuzzy rule is a control rule condensed after a large amount of control strategies and control experience are refined. Each fuzzy conditional statement gives a control rule. The control rules in the fuzzy controller this time use Mamdain control rules, and a total of $7 \times 7=49$ rules are formulated. The fuzzy rules of $\Delta K_{p}, \Delta K_{i}$ and $\Delta K_{d}$ are shown in Table 1 Table 3. 
Table 1. Fuzzy rule table of $\Delta K_{p}$

\begin{tabular}{c|ccccccc}
\hline \multirow{2}{*}{$e$} & \multicolumn{7}{|c}{$e_{c}$} \\
\cline { 2 - 8 } & NB & NM & NS & ZO & PS & PM & PB \\
\hline NB & PB & PB & PM & PM & PS & ZO & ZO \\
NM & PB & PB & PM & PS & PS & ZO & ZO \\
NS & PM & PM & PM & PS & ZO & NS & NS \\
ZO & PM & PM & PS & ZO & NS & NM & NM \\
PS & PS & PS & ZO & NS & NS & NM & NM \\
PM & PS & ZO & NS & NM & NM & NM & NB \\
PB & ZO & ZO & NM & NM & NM & NB & NB \\
\hline
\end{tabular}

Table 2. Fuzzy rule table of $\Delta K_{i}$

\begin{tabular}{c|ccccccc}
\hline \multirow{2}{*}{$e$} & \multicolumn{7}{|c}{$e_{c}$} \\
\cline { 2 - 7 } & NB & NM & NS & ZO & PS & PM & PB \\
\hline NB & NB & NB & NM & NM & NS & ZO & ZO \\
NM & NB & NB & NM & NS & NS & ZO & ZO \\
NS & NB & NM & NS & NS & ZO & PS & PS \\
ZO & NM & NM & NS & ZO & PS & PM & PM \\
PS & NM & NS & ZO & PS & PS & PM & PB \\
PM & ZO & ZO & NS & PS & PM & PB & PB \\
PB & ZO & ZO & PS & PM & PM & PB & PB \\
\hline
\end{tabular}

Table 3. Fuzzy rule table of $\Delta K_{d}$

\begin{tabular}{c|ccccccc}
\hline \multirow{2}{*}{$e$} & \multicolumn{7}{c}{$e_{c}$} \\
\cline { 2 - 7 } & NB & NM & NS & ZO & PS & PM & PB \\
\hline NB & PS & NS & NB & NB & NB & NM & PS \\
NM & PS & NS & NB & NM & NM & NS & ZO \\
NS & ZO & NS & NM & NM & NS & NS & ZO \\
ZO & ZO & NS & NS & NS & NS & NS & ZO \\
PS & ZO & ZO & ZO & ZO & ZO & ZO & ZO \\
PM & PB & NS & PS & PS & PS & PS & PB \\
PB & PB & PM & PM & PM & PS & PS & PB \\
\hline
\end{tabular}

The output of the fuzzy controller is a fuzzy set, and a de-fuzzy method needs to be used to determine an exact output. The "area halving method" is used in this article ${ }^{12}$.Use Simulink tools to establish a system simulation model composed of fuzzy controllers as shown in Figure 6 below:

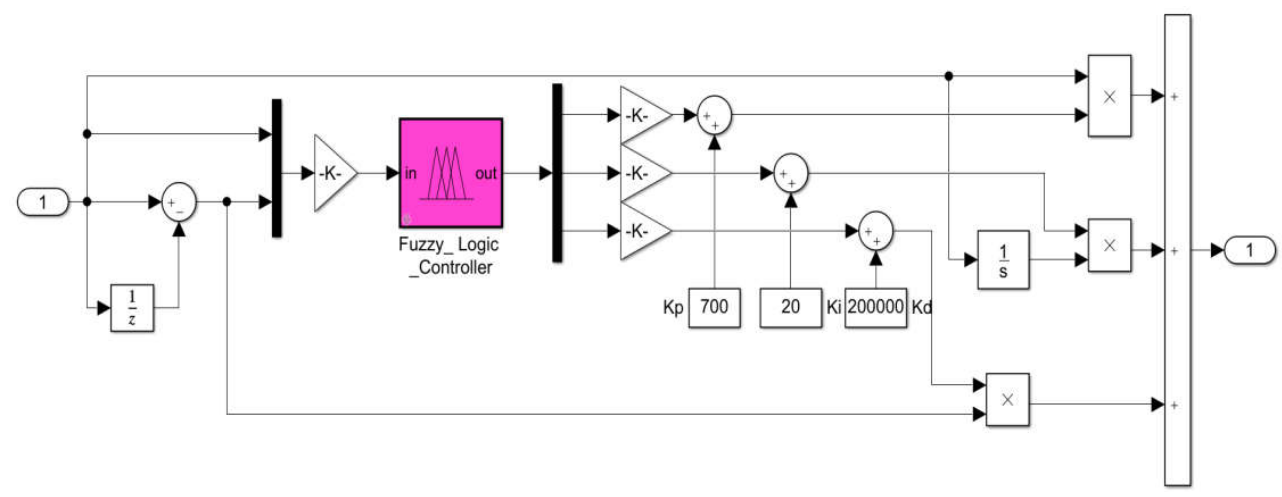

Figure 6. Fuzzy PID controller simulation model 


\section{$4 \quad$ Simulation Research}

Through the simulation in Matlab/Simulink, we can get the speed control effect of the two controller schemes in PMSM. The parameter configuration of the permanent magnet synchronous motor model selected in this simulation is shown in Table 4.

Table 4. Fuzzy rule table of $\Delta K_{d}$

\begin{tabular}{cc}
\hline Parameter & Parameter Value \\
\hline Phase & 3 \\
Back EMF waveform & Sine wave \\
Stator resistance $\mathrm{R} / \Omega$ & Salient \\
Ld $/ \mathrm{mH}$ & 0.25 \\
D phase winding inductance $(\mathrm{Lq} / \mathrm{mH})$ & 0.00545 \\
Permanent magnet flux $(\Psi / \mathrm{Wb})$ & 0.00635 \\
Number of motor pole pairs & 4 \\
Moment of inertia $\mathrm{J} /\left(\mathrm{Kg} \bullet \mathrm{m}^{2}\right)$ & 0.005 \\
\hline
\end{tabular}

In order to compare the LADRC controller and the fuzzy PID controller, simulations were carried out under three conditions. The total simulation time is $0.5 \mathrm{~s}$, and the simulation settings are as follows:

(1) $0-0.2 \mathrm{~s}$, at $0 \mathrm{~s}$, given a step Signal, set the initial target speed to $400 \mathrm{r} / \mathrm{min}$, the motor is no-load, and the load is $0 \mathrm{~N}$.

(2) $0.2-0.4 \mathrm{~s}$, at $0.2 \mathrm{~s}$, add a $10 \mathrm{~N}$ load to the motor, and the target speed remains $400 \mathrm{r} / \mathrm{min}$. The simulation waveform verifies the anti-load disturbance ability of the two control algorithms.

(3) $0.4-0.5 \mathrm{~s}$, at $0.4 \mathrm{~s}$, the target speed changes from $400 \mathrm{r} / \mathrm{min}$ to $200 \mathrm{r} / \mathrm{min}$, and the load is still $10 \mathrm{~N}$.

The simulation results using LADRC controller and fuzzy PID controller are shown in Figure 7 and Figure 8 below:

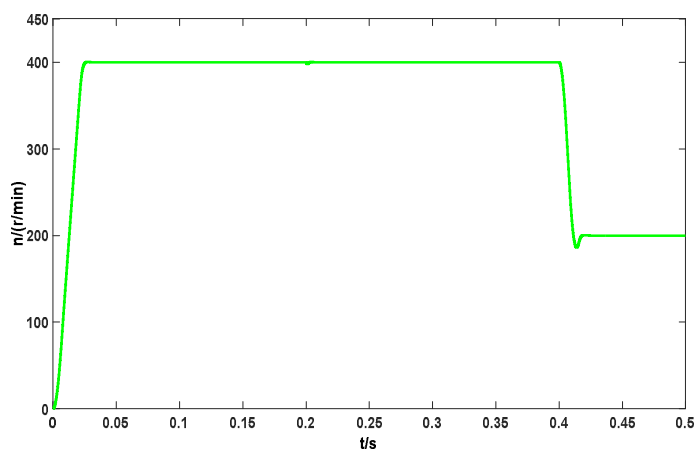

Figure 7. Simulation results based on LADRC controller

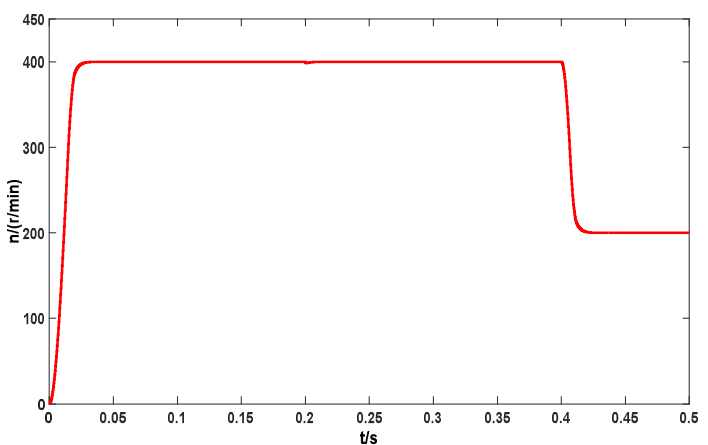

Figure 8. Simulation results based on PID controller 
It can be seen from the simulation results:

(1) At $0-0.2 \mathrm{~s}$, using LADRC control, the speed is from the initial $0 \mathrm{r} / \mathrm{min}$ to the steady state $400 \mathrm{r} / \mathrm{min}$, the adjustment time is $0.034 \mathrm{~s}$, the overshoot is $1 \mathrm{r} / \mathrm{min}$, the overshoot is $0.25 \%$, and the maximum torque is $65.5 \mathrm{Nm}$; When using fuzzy PID control algorithm, the adjustment time is $0.045 \mathrm{~s}$, the overshoot is $0.03 \mathrm{r} / \mathrm{min}$, the overshoot is $0.0075 \%$, and the maximum torque is $96.78 \mathrm{Nm}$. It can be seen that under no-load conditions, LADRC reaches a stable speed faster, takes less time, and torque fluctuations are smaller, but the overshoot is larger than the fuzzy PID control.

(2) In $0.2-0.4 \mathrm{~s}$, suddenly increase the load of $10 \mathrm{Nm}$. When using LADRC control, the minimum speed drops to $398.23 \mathrm{rpm}$, the maximum speed change rate is $0.44 \%$, the adjustment time is $0.011 \mathrm{~s}$, and the maximum torque reaches $16.18 \mathrm{Nm}$; When using the fuzzy PID control algorithm, the minimum speed is reduced to $398.32 \mathrm{r} / \mathrm{min}$, the maximum speed change rate is $0.42 \%$, the adjustment time is $0.04 \mathrm{~s}$, and the maximum torque is $12.5 \mathrm{Nm}$. It can be seen that when the load disturbance is suddenly increased, it takes less time for the LADRC control algorithm to reach the steady state, but the torque and speed change range is larger than that of the fuzzy PID.

(3) In 0.4-0.5s, when the load remains unchanged, the target speed is reduced from 400r/min to 200r/min. When the LADRC controller is used for control, the adjustment time is $0.025 \mathrm{~s}$, and the minimum speed is reduced to $186.3 \mathrm{r} / \mathrm{min}$, speed change rate is $6.85 \%$; when the fuzzy PID controller is used for control, the adjustment time is $0.04 \mathrm{~s}$, the minimum speed is reduced to $199.96 \mathrm{r} / \mathrm{min}$, and the speed change rate is $0.02 \%$. It can be seen that when there is a load, the speed drops suddenly, and the adjustment time is shorter when the LADRC control algorithm is used, but the overshoot is larger than the fuzzy PID control algorithm.

\section{Conclusion}

Due to the poor adaptability of traditional PID and weak anti-disturbance ability, the fuzzy PID control algorithm derived from it with better anti-interference ability greatly improves the anti-disturbance ability of the system, but it does not fundamentally A big problem with changing PID (The way to eliminate errors based on error feedback is very passive, lags behind the influence of disturbance, and may cause system oscillation or severe overshoot due to excessive control force); The core idea of the LADRC control algorithm is to treat the part of the system that is different from the standard type as total disturbance, and use LESO to estimate the total disturbance in real time and eliminate it with NLSEF. From the experimental simulation results, it can be seen that the anti-disturbance ability of LADRC is better in terms of adjustment time and steady-state error. However, in the process of parameter adjustment, the change law of parameters is not as easy to grasp as fuzzy PID. It is relatively difficult to adjust and exceed Tuning is larger than fuzzy PID, and the two algorithms have their own advantages and disadvantages.

Acknowledgments. The work of this paper is supported by the Southwest Minzu University Graduate Innovative Research Project (Master Program CX2020SZ87). A special acknowledgement should give to Southwest Minzu University for its experimental conditions and technical support.

\section{References}

1. JIAN YANG. Research on Sensorless Control of Interior Permanent Magnet Synchronous Motor in Zero and Low Speed[D]. Hefei University of Technology, 2018.

2. Wang Ruiming. Study on AC Servo Driven System and It's Novel Control Strategy[D]. ZheJiang: Zhejiang University, 2005.

3. ZhengWei Zhu, JianWei Zhu. Simulation Study On the Permanent Magnet Synchronous MotorSpeed Control System Based On Fuzzy Control.[J]. Journal of Changzhou Universily, 2012 (24): 61-65.

4. WenShuang Ding, YuWen Hu, WenQi Lu, JiaoYan Liang. Fuzzy PID Parameter Self-Turning Control for PMSM Servo System[J]. Small \& Special Electrical Machines, 2011, 39 (05):17-21.

5. Yi Zhi-An, Mu Chun-Miao, Sun Yin-Ping. Fuzzy Neural Network Based on Improved Particle Swarm Algorithms[J]. Computer Systems \& Applications, 2014, 23 (06): 135-140. 
6. Han Jing-Qing. From PID Technology to "Auto Disturbance Rejection Control" Technology[J]. Control Engineering of China, 2002 (03):13-18.

7. Xiong Cheng-Lin. Practical Research on Vector Control System of Induction on Motor Bsaed on Optimizing ADRC[D]. Southwest Jiaotong University, 2006.

8. Gao Zhiqiang. On the foundation of active disturbance rejection control[J]. Control Theory \& Application, 2013, 30 (12): 1498-1510.

9. Xiao Wei-Wen. Study on Direct Torque Control System of Permanent Magnet Synchronous Motor[D] .Hunan university, 2009.

10. Guo Bin, Shan Qingxiao, Xiao Changyan, Yang Jun, Liu Guohua. A Study of Beidou and GPS Dual -mode Synchronization Technology For Electric Power System Clock[J]. Computer Systems \& Applications, 2011, 19 (01): 139-141.

11. Wang Shuyan, Shi Yu, Feng Zhongxu. A Method for Controlling a Loading System Based on a Fuzzy PID Controller[J]. Mechanical Science and Technology for Aerospace Engineering, 2011, 30 (01): 166-172.

12. Zhang Jinhuan. Study and Comparison on PID Control and Fuzzy Self-Adapting PID Control Syetem[J]. Journal of Wuhan University of Technology (Information \& Management Engineering), 2005 (05): 286-290. 